\title{
Revisitando Aspectos de relações públicas
}

\author{
Revisiting Aspectos de relą̧ōes públicas
}

\section{Revisitando Aspectos de relações públicas}

\section{Fabianna Pereira Bluhm Alves}

- Publicitária graduada pela Universidade Federal do Rio de Janeiro (UFRJ)

- Profissional de mídia da McCann-Erickson.

- fabiannabluhm@gmail.com

Sebastião Amoêdo

- Doutor e mestre em Comunicação, graduado em Publicidade e Propaganda pela Universidade Federal do Rio de Janeiro (UFRJ)

- Professor adjunto da UFRJ, na qual foi coordenador do curso de Publicidade e Propaganda

- Exerceu a chefia do Gabinete da Reitoria da UFRJ

- Profissional de relações públicas

- Autor de Ética do trabalho na era da pós-qualidade e organizador de Realidade brasileira: visão universitária e Assessoria de comunicação: visão universitária

- amoedo@pobox.com 
Este artigo procura revisitar a obra Aspectos de relações públicas, de Sylla M. Chaves (1966), considerado um dos clássicos da teoria de Relações Públicas. Acrescentam-se pensamentos atualizados pelo eminente autor em entrevista idealizada e desenvolvida pelos autores do presente artigo. Aborda-se com o entrevistado inicialmente a definição de Relações Públicas e então se parte para a questão do profissional da área, passando por temas como opinião pública e "egoísmo esclarecido". Com o falecimento de Sylla Chaves em maio de 2009 , este trabalho constitui-se em um tributo à sua obra.

PALAVRAS-CHAVE: ASPECTOS DE RELAÇõES PÚBLICAS • OPINIÃO PÚBLICA • EGOÍSMO ESCLARECIDO • SYLLA CHAVES

Abstract

This text has the aim of revisiting the book Aspectos de relações públicas (Aspects of public relations), written by Sylla Chaves (1966), which is considered to be one of the classics of the Public Relations theory, adding thoughts updated by the eminent author in an interview designed and developed by the authors of this article. Initially, together with the interview, it deals with the definition of Public Relations, then goes on to the issue of professional of the area area, through using subjects like public relations and "enlightened selfishness". With the death of Sylla Chaves in May 2009, this work paper becomes a tribute to his lifetime work.

KEYWORDS: ASPECTS OF PUBLIC RELATIONS • PUBLIC OPINION • ENLIGHTENED SELFISHNESS • SYLLA CHAVES

Resumen

Se revisa la obra Aspectos de relações públicas (Aspectos de las relaciones públicas), escrita por Sylla Chaves en 1966, considerado uno de los clásicos de la teoría de las Relaciones Públicas. Se añaden pensamientos actualizados por el eminente teórico en una entrevista diseñada y desarrollada por los autores de este artículo. Primero se le solicita al entrevistado una definición de Relaciones Públicas; luego se trata la cuestión del profesional del área y se abordan temas como la opinión pública y el "egoísmo esclarecido". Con el fallecimiento de Sylla Chaves, en mayo de 2009, este trabajo se convierte en un homenaje a su obra.

PALABRAS CLAVE: ASPECTOS DE RELACIONES PÚBLICAS • OPINIÓN PÚBLICA • EGOÍSMO ESCLARECIDO • SYLLA CHAVES 
E ntre abril de 1961 e dezembro de 1962, o professor Sylla Magalhães Chaves escreveu um conjunto de ensaios na Revista do Serviço Público, os quais, posteriormente, seriam compilados pelo Serviço de Documentação do extinto Departamento de Administração do Serviço Público (Dasp), transformandose na obra Aspectos de relações públicas. Considerado um verdadeiro clássico na teoria das Relações Públicas, o livro, não obstante quase meio século de existência, ainda se mantém atual na essência do que transmite. Em entrevista concedida em 6 de dezembro de 2008, Chaves, na ocasião aposentado e dedicando seu tempo ao estudo do idioma esperanto, revisitou o tema das Relações Públicas, que, segundo ele, não são uma invenção do século XX, mas "existem há tanto tempo quanto as civilizações organizadas", uma vez que o controle da opinião pública sempre foi importante para a manutenção do poder.

O autor publicou ainda outras para melhor entendimento do tema. Uma é Relações públicas para serviços de abastecimento de água, escrita em colaboração com o Instituto Brasileiro de Administração Municipal (Ibam). Com conteúdo bastante similar ao de Aspectos de relações públicas, porém mais didático, apresenta ilustrações e um enredo de ficção. Nele o funcionário Silveira é encarregado da função de chefe de Relações Públicas do serviço de abastecimento de água no qual trabalha, mas, embora entenda muito do serviço, não é um especialista na área, sendo ajudado por Zé Tubinho, personagem criado nos moldes da Gotinha da Esso ${ }^{1}$. Em $O$ ensino de relações com o público, escrita em sequência ao curso que ministrou na Câmara dos Deputados, ele explicita a diferença entre relações públicas e relações com o público. Por fim, Publicidade e relaçôes públicas, também publicada, como as demais, na Revista do Serviço Público, explicando as diferenças fundamentais entre a publicidade comercial e relações públicas.

Sylla Chaves acreditava que, embora a época de ouro das Relações Públicas no mundo tenha se dado nos anos 1940, a disciplina estaria voltando com força na atualidade, o que, segundo ele, seria perceptível na importância crescente que as universidades vêm dando ao tema, com o surgimento de cursos superiores de Relações Públicas por todo o Brasil.

Este artigo visa, portanto, revisar os conceitos e as definições abordadas em Aspectos de relações públicas, acrescentando novos pontos de vista fornecidos pelo autor sobre as Relações Públicas, quase cinquenta anos depois de sua

1 Em 1950 os brasileiros conheceram na televisão o desenho animado que já fazia sucesso em vários países do mundo: "Esso Gubben", personagem representado por uma gota de gasolina. 0 personagem foi criação do sueco Günnar Dalin, na verdade um aperfeiçoamento do personagem apelidado de "EssoManden" (um boneco gorducho, risonho, com a cabeça imitando uma gota, em perspectiva), desenhado durante a Segunda Guerra Mundial pelo dinamarquês Vilhelm Hansen e utilizado na época para a ingrata função de desestimular a venda de gasolina, em virtude do racionamento que o mundo vivia em tempos de guerra. A empatia com o consumidor levou o personagem a correr o mundo, assimilando em cada país as suas próprias características: um par de esquis na Noruega, um suéter na Suíça ou um albornoz na Tunísia (MUNDO DAS MARCAS, 2006) 
publicação. Há também a adição de explicações interessantes de Sylla Chaves sobre suas outras obras acerca do tema.

Relações Públicas

Definição

Segundo Sylla Chaves (1968, p. 20) as Relações Públicas são uma

função administrativa por meio da qual uma organização, ora informando e guiando a opinião pública, ora pesquisando-a e deixando-se por ela guiar, busca identificar o seu interesse privado com o interesse público, desincumbindo-se de suas obrigações para com a sociedade e conseguindo e mantendo a compreensão, a aquiescência e o apoio desta.

Partindo dessa definição, o professor, reproduzindo o famoso quadro dos campos de atividade (CHAVES, 1966, p. 47), apresentado por Edward Bernays (1966, p.48), ainda defende que, embora seja necessário que as Relações Públicas influenciem a opinião pública, isto deve se dar com ênfase no âmbito da educação e da divulgação, parcialmente no âmbito da persuasão, mas jamais no âmbito da coação.

Assim sendo, entende-se divulgação como um comunicado sem juízos de valor, normalmente enviado aos veículos de comunicação com o intuito de informar a opinião pública sobre quaisquer fatos novos que digam respeito à organização. Ao contrário da coação, que visa persuadir buscando benefícios da comunidade, a educação também persuade, mas, ao contrário, busca beneficiar a comunidade na qual a organização atua.

Dessa forma, para ele, existem as boas Relações Públicas - aquelas que se fundamentam em práticas éticas pautadas nos princípios gerais da atividade - e as más Relações Públicas - as que atuam por meio de coação, ou seja, impondo um modo de pensar à comunidade, sem nada lhe oferecer em troca.

Nas boas Relações Públicas, contudo, existe uma bilateralidade, uma relação de mutualidade entre a organização e a comunidade: a organização beneficia a comunidade com suas Relações Públicas, por meio de programas que a façam mais bem vista perante a opinião pública e, desse modo, a comunidade se beneficia desses programas.

Para além de definir as Relações Públicas como altruísmo ou "egoísmo esclarecido" ", Sylla Chaves entendia que, seja da maneira que for, existe, nas

2 A expressão "egoísmo esclarecido" só surgiu há poucos anos. Nos Estados UNidos, talvez em função das peculiaridades de sua formação. Desde seu passado colonial os americanos aprimoraram a capacidade de defender seus interesses por si próprios sem contar com a atuação do Estado ou de qualquer outra 
boas Relações Públicas, uma relação de simbiose, em que ambas as partes saem beneficiadas. Ele enxergava isso nas ações culturais, sociais ou ambientais promovidas atualmente por muitas empresas: a responsabilidade social, muito em voga hoje em dia, é um claríssimo exemplo de boas Relações Públicas. A empresa atua de forma positiva sobre a comunidade com ações desse tipo e, dessa maneira, desde que as informações sejam sempre verdadeiras, tem todo o direito de divulgar amplamente seus programas, recebendo todo o crédito e admiração da opinião pública por isso.

Informação, orientação e pesquisa

Sylla Chaves defendia que os dois objetivos básicos das Relações Públicas são a harmonia e a eficiência, sendo que ambos estão intimamente interligados. Para alcançá-los, é necessário que as Relações Públicas atuem em suas três funções primordiais: informar, orientar e pesquisar.

Segundo ele, em uma democracia, é essencial que as organizações prestem contas à opinião pública, além de dissipar mal-entendidos: um público corretamente informado não exigirá da organização aquilo que ela não é capaz de realizar, além de que será muito mais paciente ao esperar por aquilo que sabe já estar sendo providenciado. Ademais, depois de um trabalho bem executado, a informação deve ser dada para que a organização receba o crédito merecido. Ele chama a atenção, contudo, para as Relações Públicas não se transformarem em propaganda indevida, roubando o mérito de organizações para transferi-los a determinados indivíduos, algo muito recorrente na política.

Quanto à orientação, cabe ao profissional de relações públicas também buscar o apoio e a cooperação do cidadão, que, supostamente, é leigo na expertise da organização. Dessa forma, ele precisa ser primeiro orientado, para que, então, aceite colaborar. Ou seja, a orientação deve ser efetuada para ensinar o melhor uso do produto ou serviço da organização, combater vícios arraigados e obter apoio e colaboração.

A pesquisa é fundamental para nortear o trabalho de Relações Públicas: é necessário saber como a comunidade pensa e do que necessita, para, a partir daí, saber o que deve ser feito para melhor servi-la. Além disso, por meio da pesquisa, é possível descobrir as falhas da organização diante da opinião pública, podendo, então, corrigi-las.

autoridade maior. Ao mesmo tempo desenvolveram um espírito comunitário incomum. Assim egoísmo esclarecido é se assumir explicitamente como individualista e egoísta e não se envergonhar disso, porque, por outro lado se é consciente e esclarecido quando os problemas são gerais, Em tal situação todos participam e jamais se gabam ou se vangloriam (NETO, 2009). 
Ao expandir conceitos de autores diversos das décadas de 1940 e 1950, Sylla Chaves (1968, p.30) apresenta os princípios gerais de Relações Públicas, como: bilateralidade, onipresença, continuidade, flexibilidade, especificidade e autoridade ${ }^{3}$.

A bilateralidade, para ele, está contida na própria definição de Relações Públicas, mostrando a necessidade de reciprocidade comunicacional e de simbiose entre a organização e a comunidade, ensejando o conceito de "via de duas mãos" . O programa de Relações Públicas deve colocar o interesse público ao menos no mesmo patamar que o próprio interesse da organização. Para se obter aceitação pública, é imprescindível entender que o apoio só é obtido por meio de um contribuinte ou consumidor satisfeito. Por esse princípio, depreende-se que o setor de Relações Públicas de uma organização deve falar sempre em termos de interesse público e, além disso, deve também estar aberto às críticas e sugestões da comunidade.

O princípio de onipresença das Relações Públicas significa que suas atividades devem estar presentes em todos os processos da organização, ou seja, cada funcionário, cada instalação deve transmitir seus valores e suas crenças como personalidade jurídica. Mesmo o funcionário de cargo mais baixo, no momento de contato com o público, passa a ser o responsável pelas Relações Públicas da organização, pois o seu tratamento, sua cordialidade e sua prestatividade gerará no público um juízo de valor, positivo ou negativo. Dessa forma, é necessário que as Relações Públicas sejam atuantes em todos os níveis.

Quanto ao princípio de continuidade, Sylla Chaves defendia a natureza educativa de boa parte do trabalho de Relações Públicas, sendo exercido de forma lenta e permanente. Assim, ele acreditava que o diálogo ensejado pelas atividades de Relações Públicas não pode jamais cessar, já que isso prejudicaria as relações com o público, que pode ter críticas a apresentar ou dúvidas a serem esclarecidas. Embora esse trabalho possa se dar por meio de campanhas curtas, elas devem funcionar sempre em um processo sucessivo e contínuo.

3 No ano 1953 Sylla Chaves foi assistente e intérprete do primeiro curso regular de Relações Públicas promovido pela Organização das Nações Unidas (ONU), em conjunto com a Escola Brasileira de Administração Pública (Ebap), da Fundação Getúlio Vargas (FGV). Inaugurado sob a regência do Prof. Eric Carlson, a este se juntaram o Prof. Hawood Childs, da Universidade de Princepton, e o técnico britânico Neville Shepherd. Sylla Chaves foi ainda o tradutor da obra Relações públicas, propaganda e opinião pública, de Childs editada pela FGV em 1954. Durante esse período considerava-se que a fundamentação de Relações Públicas se encontrava em "estado fluido", razão por que, ao analisar as ponderações de Sylla Chaves em suas obras, podemos inferir que os princípios gerais de Relações Públicas foram por ele compilados após ouvir fontes diversas e a partir daí reproduzidos por todos os demais autores brasileiros.

4 Edward L. Bernays, da Universidade de Oklahoma, sobrinho de Sigmund Freud, que the transmitiu o gosto pelas Ciências Sociais, utilizou a expressão "rua de duas mãos" para explicitar que a atividade de Relações Públicas não apenas ausculta como também influencia a opinião pública (CHAVES, 1963, p. 10). 
A flexibilidade está presente no fato de que o programa de Relações Públicas de uma organização deve ter uma rotina, mas não pode ser rígido. Para Sylla Chaves, as mais importantes ocasiões para a prática de Relações Públicas são as mais imprevisíveis, os verdadeiros incêndios, sendo necessário que o profissional da área atue como um gestor de controvérsias, flexibilizando seu programa sempre que necessário.

A respeito da especificidade Sylla Chaves esclarecia que o trabalho de Relações Públicas deve ser feito sob medida para uma organização concreta, ou seja, não é possível reproduzir o programa de Relações Públicas bemsucedido de uma organização em outra. É necessário que o programa leve em consideração as necessidades específicas daquela organização e da comunidade em que ela atua.

O princípio de autoridade, como se explicará mais adiante, se explicita pela necessidade de que as Relações Públicas atuem no nível máximo de autoridade de uma organização. Isso porque as Relações Públicas, conforme o princípio de onipresença, devem estar presentes não somente no setor específico, mas se espraiar em todos os setores. Apenas atuando no nível mais alto de autoridade da organização será possível coordenar todo o trabalho que lhe diz respeito.

0 profissional de relações públicas

\section{Formação}

Para Sylla Chaves, as Relações Públicas atuam sobre três instâncias: a organização, a opinião pública e as comunicações recíprocas.

A primeira instância, a organização, é o "sujeito", ou seja, aquele a partir do qual se devem aprimorar as Relações Públicas. A segunda instância, a opinião pública, é o "objeto", a ser permanentemente trabalhado, guiando as Relações Públicas e sendo por elas guiado. Segundo Sylla Chaves, uma opinião pública informada, satisfeita e disposta a colaborar é a melhor prova de que as Relações Públicas são boas, da mesma forma que uma opinião pública que ignora a organização, ou lhe é hostil e não deseja colaborar, fornece diagnóstico seguro de que as Relações Públicas são más. Já a terceira instância, as comunicações recíprocas, são constituídas por contatos pessoais diretos - telefone, internet, carta - , imprensa, visitas dirigidas, recortes de jornais, em suma, todos os encontros com o público, informando-o e sendo informado por ela. Chaves enfatizava ainda a importância de que essas comunicações sejam sempre bilaterais.

A partir dessa explicação, ele definia o bom profissional de relações públicas como um excelente conhecedor da organização, da comunidade na qual essa organização atua e, por fim, também um grande conhecedor de todas as formas de comunicação existente entre elas. Essas características, para ele, são 
mais importantes do que uma excelente formação universitária, embora a formação universitária possa ajudar o profissional.

Ele, contudo, não defendia necessariamente uma formação específica em Relações Públicas, apesar de afirmar não ser contra nenhuma formação universitária. Sylla Chaves acredita até que seja possível reunir algumas disciplinas importantes para a formação do profissional de relações públicas em um curso único. No entanto, crê que o bom relações-públicas é uma pessoa de grande credibilidade e experiência na organização e insiste, tal qual afirmou quase cinquenta anos atrás, em Aspectos de relações públicas, que o profissional deve estar, invariavelmente, ao lado da principal autoridade da organização, isso quando a função de relações-públicas não é executada pela própria autoridade. Isso se justifica, segundo ele, pelo fato de que as Relações Públicas efetivas atuam em todos os âmbitos da empresa, tanto interna quanto externamente, de modo que somente alguém com muito poder na organização será capaz de efetuar as mudanças necessárias para melhores Relações Públicas.

Dessa forma, para ele, a formação de Relações Públicas demanda tanto noções de Administração quanto de Ciências Sociais e Comunicação, de modo que uma disciplina de Relações Públicas deveria estar presente em quaisquer cursos universitários dessas áreas. Contudo, um curso em Relações Públicas por si só não basta, uma vez que se trata de uma expertise extremamente multidisciplinar, a qual, além dos conhecimentos específicos da área, demanda igualmente uma grande bagagem de cultura geral e tato com pessoas, o que, segundo ele, só é conseguido por meio da experiência. Além disso, ele acreditava que a função de relações públicas só é alcançada no topo da carreira, já que, como explicado, o relações-públicas ou é a autoridade máxima de uma organização ou seu braço direito, um consultor permanente. Assim, durante a entrevista, ele também defendeu a formação em Relações Públicas como uma especialização do profissional já formado.

\section{A função do profissional}

Em Aspectos de relações públicas, Sylla Chaves cita Bernays (1966, p. 42), segundo o qual o profissional de relações públicas deve ser um especialista capaz de agir não só sobre as massas quanto também sobre a organização que o contratou. Dessa forma, cabe a ele definir os objetivos sociais da organização, ou ajudar a encontrá-los; descobrir os desajustes presentes nesses objetivos e os vários elementos da comunidade, dos quais a organização depende; ajustar as necessidades da organização às necessidades da comunidade para solucionar esses desajustes; e, por fim, aconselhar a organização quanto a maneiras como suas políticas e ações podem se tornar compreensíveis à opinião pública.

Assim sendo, reitera-se que as Relações Públicas de uma organização são responsáveis por encontrar a interseção entre os interesses desta e os dos públi- 
cos, potencializando ao máximo essa interseção. É essencial, para Sylla Chaves, que o relações-públicas de uma organização seja um grande conhecedor e interpretador da opinião pública.

A função do profissional de relações públicas é essencialmente consultiva: apresentar à autoridade máxima da organização o ponto de vista da opinião pública, estando presente em todas as reuniões importantes. Nenhuma decisão na organização deve ser tomada sem prévia consulta ao Relações Públicas. Além disso, é necessário que este profissional atue de diferentes maneiras sobre os diferentes públicos da organização, que carecem ter suas demandas atendidas como convém a cada um. É necessária uma atuação tanto sobre o público externo e meios de comunicação como também sobre os funcionários da organização.

Sylla Chaves compara o bom relações-públicas a um consultor jurídico de natureza preventiva, diferente do advogado que atua com a controvérsia contenciosa - que já está na esfera do sistema judiciário. Em sua concepção o relações-públicas, tal qual o consultor, deve saber dizer o que não fazer, sendo capaz de impedir o erro antes que este aconteça, para que não seja necessário defendê-lo posteriormente.

\section{Relações públicas versus relações com o público}

A partir do princípio de onipresença das Relações Públicas, entende-se que todo funcionário é potencialmente responsável pelas relações públicas da organização, já que cada encontro com esta gera no público um juízo de valor acerca da mesma. Dessa forma, no momento de contato com o público, seja o funcionário um porteiro, uma recepcionista, um ascensorista etc., ele é o legítimo responsável pelas relações públicas de uma organização. Entretanto, cabe diferenciar relações públicas de relações com o público.

As relações com o público são parte das Relações Públicas e essenciais para que estas sejam boas, mas o conceito de relações públicas, como se viu, abrange outros aspectos. Sylla Chaves defendia que todos os funcionários da empresa sejam treinados para melhor atender o público. As Relações Públicas, sendo onipresentes, devem agir primeiramente sobre o empregado, conquistando-os para o programa de Relações Públicas da organização. O funcionário deve poder agir bem, ou seja, ser corretamente selecionado; $s a$ ber agir bem, ou seja, ser corretamente treinado; e, finalmente, ele deve querer agir bem, achando-se satisfeito, integrado e motivado. Embora a seleção do funcionário esteja fora do seu escopo, cabe ao chefe de Relações Públicas a tarefa de treiná-lo, para que ele saiba agir bem, e, parcialmente, colaborar para que ele queira agir bem. 
Sendo representante da organização, a partir do momento em que porta o crachá o público interno deve ser o primeiro a ser envolvido pelos programas de Relações Públicas. Sylla Chaves cita uma experiência pessoal de um caso de ausência de interação com o público interno no qual atuou como consultor. Um banco de um grande Estado brasileiro passava por uma dificuldade com o público externo: uma agência de publicidade contratada havia criado um produto inovador para o banco e o anunciado intensamente. Entretanto, nas agências bancárias do interior do Estado, os gerentes não haviam sido informados desse produto, o que fez com que não atendessem às demandas do público local, interessados no novo produto. Parece elementar, mas o problema ainda ocorre eventualmente nos dias de hoje.

\section{Relações com a imprensa}

Como a opinião pública é constantemente influenciada pelos meios de comunicação, que vivem de notícias, é importante fornecer-lhes constantemente fatos que sejam verídicos, atuais, originais e interessantes. Não basta escrever bem, é necessário saber também pesquisar, interpretar o noticiário como meio de "mensurar a opinião pública". O profissional de relações públicas deve ser capaz de selecionar as informações que têm valor jornalístico e repassá-las por meio de comunicados, entrevistas coletivas ou contatos diretos.

\section{Gestão de crises}

A função estratégica do gestor de relações públicas em momentos de crise é fundamental. Sylla Chaves cita a importância da atividade principalmente em momentos de tragédias, como no caso de acidentes aéreos, quando é necessário confortar a família das vítimas, explicar as causas dos acidentes, tomando as medidas mais adequadas para que a imagem da empresa fique ferida o mínimo possível. Nesses momentos, pontua, é necessário sempre ser o mais ágil em suas ações, liberando rapidamente informações e indenizações.

Ele defende ainda que o mais importante, em caso de erros, é admiti-los, como no caso da Tennessee Valley Authority ${ }^{5}$, que, depois de reconhecer que se encontrava em estado de calamidade, pôde contar com a colaboração do público. Enfim, tudo aquilo que afeta a opinião pública deve ser antecipado, e é importante que a notícia parta antes da própria organização, para que a opinião pública não se sinta enganada.

5 Sylla Chaves faz citação oral da importante empresa americana criada no programa de recuperação econômica da década de 1930. A controvérsia sempre está presente em tal criação, haja vista que o empreendimento governamental é considerado nos Estados Unidos da América como estatismo, indo de encontro com o liberalismo empreendedorista de sua sociedade. 


\section{Considerações finais}

Quase meio século se passou desde a publicação do primeiro ensaio acerca do tema Relações Públicas na Revista do Serviço Público. No entanto, a despeito do tempo, a essência da obra de Sylla Chaves se mantém atual e aplicável nos dias de hoje, quando há a intenção de executar o que ele chama de "boas Relações Públicas".

O que se conclui é que, mesmo em um mundo mais globalizado, mais informatizado do que há tantos anos, o surgimento de novos meios, como a internet, e de novos clientes, como artistas e jogadores de futebol, no lugar de instituições públicas e privadas, estes constituem apenas novos meios e clientes a serem trabalhados pelos profissionais de relações públicas. O fundamental permanece naquilo definido por Sylla Chaves, um permanente e fiel defensor das boas Relações Públicas, da ética na profissão, e, sobretudo, um crítico das instituições que insistem em fazer as "más Relações Públicas": a propaganda vazia e mentirosa que se preocupa mais com o invólucro do que com o produto em si.

Muito daquilo que veio a ser publicado depois de sua conceituada obra Aspectos de relações públicas representa, não raro, apenas uma nova abordagem de sua fundamentação teórica. Novos termos e novas expressões são criados, mas a essência dos velhos mestres é a mesma. Sylla define as comunicações bilaterais ou interativas, hoje se fala de "mídias sociais" e da capacidade interativa da internet. Nada que ele não tenha adiantado, mesmo sem dispor da moderna tecnologia da informação. Já então Sylla defendia as "boas Relações Públicas" que hoje se apresentam como "responsabilidade social".

Os princípios básicos ou gerais ${ }^{6}$ das Relações Públicas, compilados por Sylla Chaves não foram até hoje suprimidos ou ampliados, quando muito enunciados diferentemente de sua expressão original, o que comprova a visão de futuro daqueles professores da década de 1950.

Curioso notar em sua obra Relações públicas para serviços de abastecimento de água um item destinado a conceituar a "comunicação em massa" (CHAVES, 1968, p.57), quando só se falava em "comunicação de massa", descortinando o que muito mais tarde seria redenominado como "grupos de encontro" (NALLO, 1999), conclusão baseada na obra do alemão Gerd Gerken (1994) sobre a morte do marketing, publicada no idioma original em 1990.

As inúmeras citações de Sylla Chaves em suas obras representam um verdadeiro banco de dados sobre a teoria das Relações Públicas, que se mantêm atualizadas nessa primeira década do século XXI.

6 Que não se confundam esses com os princípios diretores de Childs, apresentados no Brasil ao longo do curso ministrado por ele na Fundação Getúlio Vargas. 
Quanto mais a tecnologia desenvolve a capacidade informacional e interativa dos novos meios, mais e mais as demandas por novas informações fazem evoluir a criticidade dos inúmeros públicos ou grupos que constituem a sociedade, a exigir com vigor crescente a ética nas decisões e a transparência das atitudes. Com a adoção das boas práticas de Relações Públicas uma organização ou personalidade não temerá a sociedade do escândalo ${ }^{7}$ em que vivemos.

O egoísmo esclarecido, para ele, continuava válido no sentido de que haveria uma relação de simbiose entre a organização e a comunidade. Defendeu até o fim - talvez um pouco utopicamente, como continuava belamente a defender o esperanto como meio de resolver as divergências entre as culturas - a necessidade de este egoísmo ser mais esclarecido do que egocentrista.

Falecido a 30 de maio de 2009, perto de completar 80 anos, as cinzas de Sylla Magalhães Chaves foram depositadas aos pés de um cambucá. Essa árvore, nativa da Mata Atlântica, foi escolhida por ele já que seus frutos são saborosos e fazem bem ao estômago, sendo procurados por várias espécies de pássaros, podendo por isso ser empregada em reflorestamentos mistos destinados à recomposição de áreas degradadas. A presença desse grande mestre será constante, enquanto houver procura por alimento e interesse pela restauração das boas relações entre o ser humano e a natureza que sustenta a vida.

\section{Referências}

CHAVES, Sylla M. Revisitando "Aspectos de relações públicas". Entrevista concedida a Fabianna Pereira Bluhm Alves. Rio de Janeiro, 06 dez. 2008.

\footnotetext{
. Aspectos de relações públicas. Rio de Janeiro: Dasp, 1966.

0 ensino de relações com o público. Revista do Serviço Público. Rio de Janeiro: Dasp, 1963.

. Publicidade e relações públicas. Revista do Serviço Público. Rio de Janeiro: Dasp, 1963.

. Relações públicas para serviços de abastecimento de água. Rio de Janeiro: Instituto Brasileiro de Administração Municipal (lbam), 1968.

GERKEN, Gerd. Addio al marketing. Torino: Isedi, 1994.

MUNDO DAS MARCAS. Uma gotinha consagrada. Disponível em: <http://mundodasmarcas.blogspot.com/2006/06/esso-weredrivers-too.html >. Acesso em: jun. 2009.

NALLO, Egeria Di. Meeting points. São Paulo: Cobra Editora e Marketing, 1999.

NETO, João Mellão. Egoísmo esclarecido. 0 Estado de S. Paulo, 16 jan. 2009.

7 A sociedade do escândalo se manifesta nessa primeira década de século XXI pelo fácil acesso de qualquer cidadão à tecnologia da informação, quando por meio da rede mundial de computadores é possível divulgar uma denúncia para milhões de pessoas em todo o mundo.
} 